\title{
A glomus tumour beneath the painful unpolished nail
}

\author{
Raymond E. Anakwe MB ChB, Jane E. McEachan MB ChB
}

Previously published at www.cmaj.ca

A 68-year-old woman presented with a three-month history of a very painful left thumb. She denied any history of injury and reported new hypersensitivity to cold of the same thumb nail. On examination, she had exquisite tenderness at the nail fold. The patient had well kept and polished nails with the exception of the symptomatic thumb, which was trimmed but unpolished (Figure 1). She reported that polishing the nail was too painful. A diagnosis of glomus tumour was made and surgical excision undertaken. This confirmed the diagnosis and resolved her symptoms.

Glomus tumours are rare and usually benign lesions arising from the vascular and thermoregulatory glomus body of the skin. ${ }^{1}$ They are commonly but not exclusively related to the nail bed. The diagnosis is usually made on the basis of the clinical history and examination. ${ }^{2}$ Plain radiographs may show "scalloping" of the distal phalanx; however, the absence of changes on plain radiographs does not exclude a glomus tumour. Further imaging may show the tumour. Duplex ultrasonography or magnetic resonance imaging are particularly useful and enhance the detection of multiple lesions. ${ }^{1}$

The classic history is of paroxysmal pain, focal tenderness and hypersensitivity to cold. ${ }^{1,2}$ Patients may avoid using the affected digit. This can be a difficult diagnosis to make as there may be very little to find on examination. Patients may notice a bluish discoloration beneath the nail, and the nail fold may become elevated as the tumour proliferates within the enclosed space. The differential diagnoses should include local infection or osteomyelitis, osteoid osteoma, painful conditions of the nail, malignancy and inclusion cysts.

The treatment is surgical excision and the prospects for complete resolution of symptoms are good if excision is complete. Recurrence is unusual and is most likely related to incomplete excision or undetected multiple lesions. ${ }^{3}$ Malignant change has been reported but is extremely rare. Malignant glomus tumours are usually locally invasive, although they may metastasize. ${ }^{4}$

From The Hand Service, Department of Trauma and Orthopaedic Surgery, Queen Margaret Hospital, Dunfermline, Scotland

CMAJ 2010. DOI:10.1503/cmaj.091645

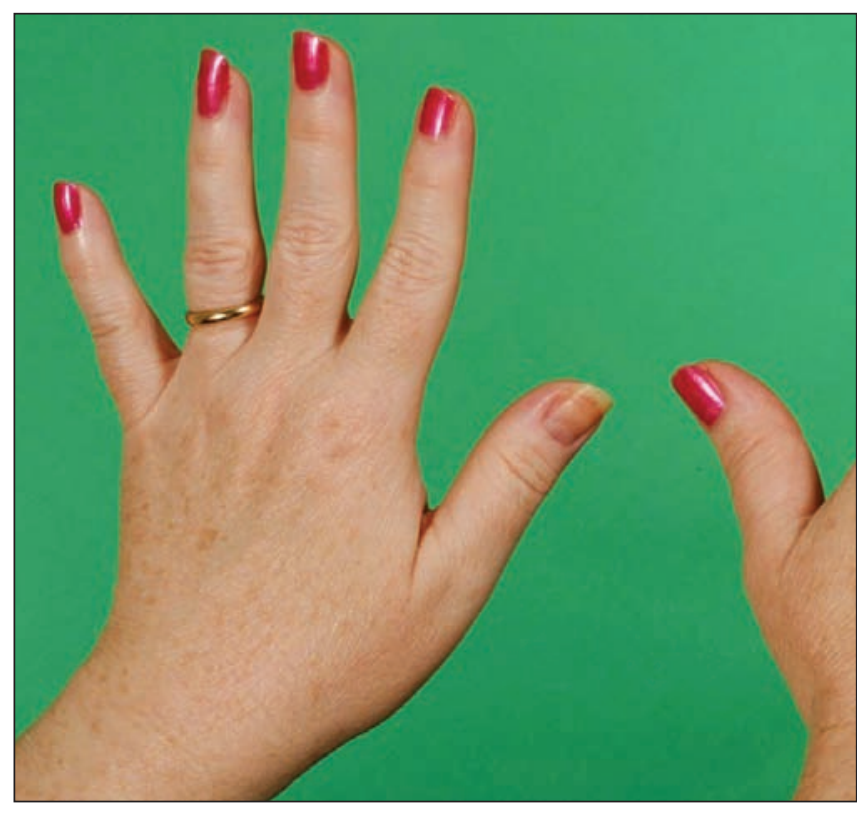

Figure 1: The unpolished nail of a 68-year-old woman with a three-month history of a painful left thumb.

Given the paucity of reliable clinical signs, a high level of suspicion is required to make the diagnosis on the basis of a good history, supported when necessary with imaging. Presentation with a painful and unpolished or untrimmed finger nail, particularly when the history is suggestive, should alert the clinician to the possibility of an underlying glomus tumour.

This article has been peer reviewed.

Competing interests: None declared.

\section{REFERENCES}

1. McDermott EM, Weiss AP. Glomus tumors. J Hand Surg [Am] 2006;31:1397-400.

2. Cigna E, Carlesimo B, Bistoni G, et al. The value of clinical diagnosis of digital glomus tumors. Acta Chir Plast 2008;50:55-8.

3. Favarger N. Glomus tumor of the hand. In: Egloff DV, editor. Tumors of the hand. London (UK): Taylor and Francis; 2004. p. 47-53.

4. Oh SD, Stephenson D, Schnall S, et al. Malignant glomus tumor of the hand. Appl Immunohistochem Mol Morphol 2009;17:264-9. 